\title{
A la revista VERBA HISPANICA en su décimo aniversario
}

Es un honor para mí felicitar como decana de la Facultad de Filosofía y Letras de la Universidad de Ljubljana a la revista VERBA HISPANICA, justo cuando sale a la luz su décimo número, y cuando las Cátedras de Lengua y Literatura Españolas cumplen veinte años de funcionamiento. La revista se publicó por primera vez en 1991, a los diez años de haberse creado la Sección de Hispánicas en el Departamento de Lenguas y Literaturas Romances de nuestra Facultad; parecía un reto osado entonces, pero el número de contribuciones recibidas en estos diez años demuestra que fue una decisión acertada. En los últimos años, ha crecido el número de artículos de hispanistas eslovenos, lo que sin duda prueba la enorme fortaleza de los estudios de las lenguas y literaturas iberorromances en nuestro país. La publicación de tesis doctorales y tesinas, así como de algunos de los mejores trabajos de graduación, demuestra que la pujanza de la Sección de Hispánicas y el crecimiento de la revista van a la par.

La revista VERBA HISPANICA, además, no ha tenido nunca un carácter cerrado, sino, muy al contrario, desde el primer número, ha abierto sus páginas a los hispanistas de todas las latitudes y corrientes de pensamiento. La colaboración de especialistas extranjeros es para nosotros una grata satisfacción y nos alenta al trabajo de cara al futuro. Consideramos especialmente preciosas las colaboraciones provenientes de hispanistas eslovenos que han continuado sus carreras universitarias en el extranjero, sobre todo, en el área cultural hispanoamericana, contribuyendo al desarrollo de su especialidad. En nombre de la Facultad de Filosofía y Letras de la Universidad de Ljubljana y en el mío propio, deseo agradecer al Comité de Redacción el trabajo realizado, y a la Embajada del Reino de España, el apoyo financiero que lo ha hecho posible todos estos años. La revista VERBA HISPANICA representa hoy uno de los enclaves de la investigación científica en nuestra facultad y un estímulo para nuestros estudiantes. Les deseo el mayor de los éxitos para el futuro, y sólo me queda pedir que mantengan el mismo entusiasmo investigador que fundó la revista, y que se ha convertido en su línea rectora desde entonces.

Profesora Dra. Neva Šlibar Decana de la Facultad de Filosofía y Letras de la Universidad de Ljubljana 